\title{
الاشراف التربوى فى مصر الواقع وإلمأمول
}

إعداد

\section{دكتوره / سلاف محمل أحمد}

دكتوراه الفلسفة فى التربية

قسم التعليم العالى والتعليم المستمر - جامعة القاهرة

معلم خبير بوزارة التربية والتعليم

\section{ملخص البحث}

الاشراف بصفة عامة هو عملية تفاعل متبادل في اتجاهين تتضمن توجيه ونصح وارشاد وتوعية ورقابة وتقييم وتقويم من جانب المشرف للمشرف عليه بهدف تتمية قيم ومعارف ومهارات وسلوك وشخصية

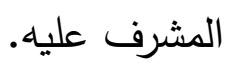

والاشراف التربوي يمثل دوراً حيوياً في إنجاح العملية التعليمية والنظام التربوي من حيث أنه يلعب دوراً كبيراً في إنارة السبيل أمام العاملين في الحقل التعليمي. كما أنه عملية فنية شورية قيادية إنسانية شاملة، غايتها تقويم وتطوير العملية التربوية والتعليمية بكافة محاورها، تهدف إلى تحسين التعليم من خلال رعاية التهاية وتوجيه وتنشيط النمو المستمر لكل من الطالب والمعلم والمشرف ذاته.

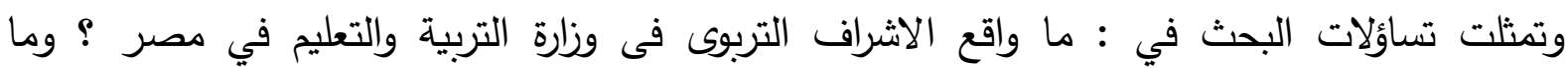
مقترحات تحسين الاشراف التربوى فى وزارة التربية والتعليم في مصر ؟

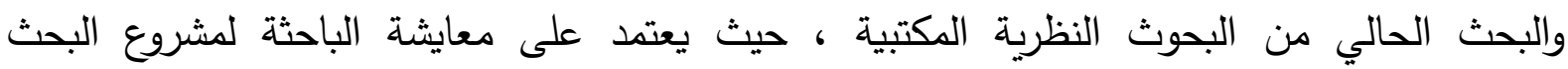
ومجموعة من الدراسات الميدانية لمجموعة من المدارس، الخبرة الثخصية والمقابلات المتعددة حول الموضوع مع عدد من المشرفين التربويين فى محافظتي القاهرة والجيزة. وقدم البحث شرحا وافيا لكل من مفهوم الاشراف التربوي وتطوره وخصائصه ومميزاته ومبادئه والمعوقات التي تواجهه. وفي النهاية تم تقديم مجموعة من التوصيات التي يمكن أن تساهم في تطوير وتحسين 


\title{
Educational supervision in Egypt, Reality and Hope
}

\author{
BY \\ Dr. Sulaf Muhammad Ahmad
}

\author{
Doctor of Philosophy in Education \\ Department of Higher Education and Continuing Education - Cairo University \\ Expert teacher at the Ministry of Education - Egypt
}

\begin{abstract}
Supervision in general is a two-way reciprocal interaction process that includes guidance, advice, counseling, awareness, monitoring, assessment and evaluation by the supervisor to other party, with the aim of developing the values, knowledge, skills, behavior and personality.

Educational supervision represents a vital role in the success of the educational process and the educational system in that it plays a major role in illuminating the path for workers in the educational field.

It is also a comprehensive human, leading, technical, consultative process, whose aim is to evaluate and develop the educational process in all its axes, aiming to improve education by sponsoring, directing and activating the continuous growth of the student, the teacher, and the supervisor himself.

The research questions were: what is the reality of educational supervision in the Ministry of Education in Egypt? And what are the proposals or recommendations to improve the educational supervision in the Ministry of Education in Egypt?

The current research was a theoretical office research, as it depends on the researcher's experience of the research project and a group of field studies for a group of schools, personal experience and multiple interviews on the subject with a number of educational supervisors in the governorates of Cairo and Giza. The research provided a full explanation of each of the concept of educational supervision, its development, characteristics, advantages, principles, and the obstacles it faces. In the end, a set of recommendations were presented that could contribute to developing and improving educational supervision in Egypt.
\end{abstract}

key words :

Supervision, educational supervision, educational process 
الاشراف Supervision بصفة عامة هو عملية تفاعل متبادل في اتجاهين تتضمن توجيه ونصح وارشاد وتوعية ورقابة وتقييم وتقويم من جانب المشرف للمشرف عليه بهدف تتمية قيم ومعارف ومهارات وسلوك وشخصية المشرف عليه ( مدحت أبو النصر : 2020 ، 123 ).

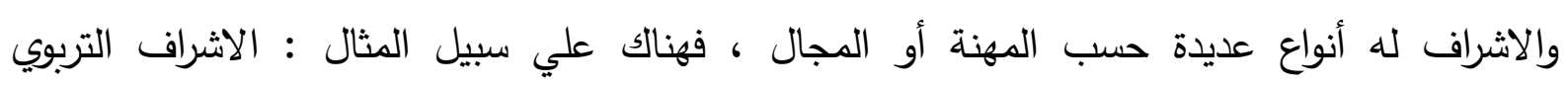

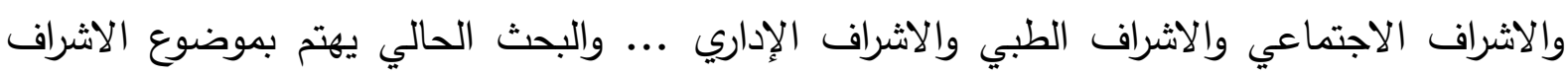
التربوي.

فالاشراف التربوي Educational Supervision يمثل دوراً حيوياً في إنجاح العملية التعليمية والنظام

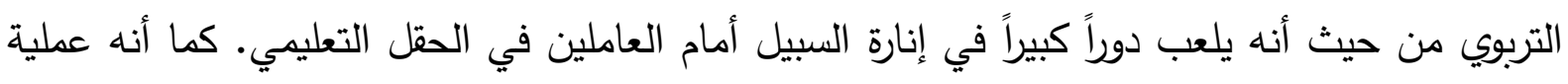

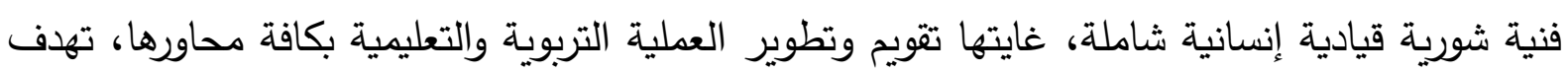

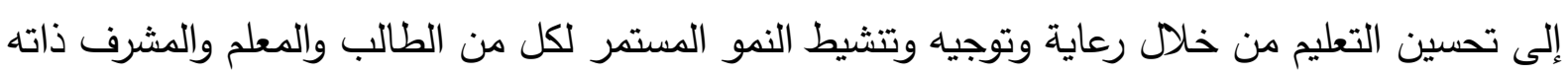

$$
\text { ( سلامه عبد العظيم : } 2013 \text { ، } 45 \text { ). }
$$

والمشرف يجب أن يشخص الموقف التعليمي ويقيم المعلم ، ويبرز ما فيه من قوة أو ضعف، ويوجه

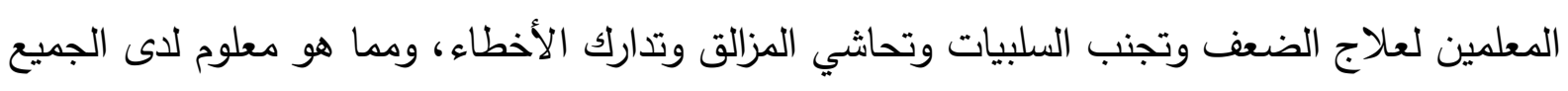

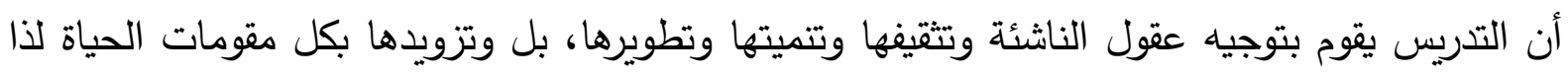

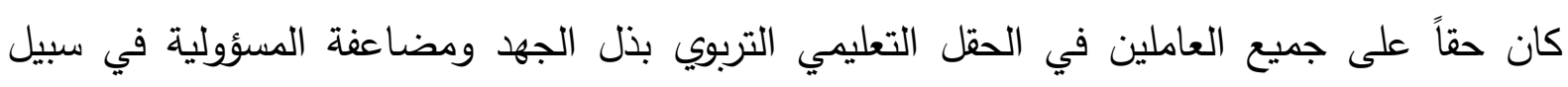

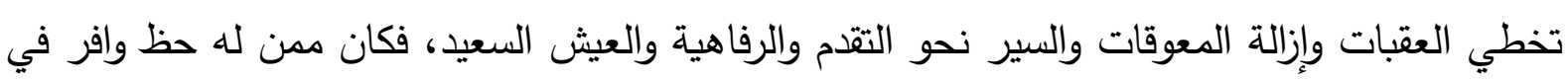
هذا المجال هو المشرف التربوي، إذ بنجاحه تزدهر النتائج وتحقق الآمال ويتقدم المجتمع بلبناته المعطاءة المتوثبة نحو العلا والمجد وإضاءة سبل الآخرين. والجميع يشهد أن المشرف التربوي عليه عبه ثقيل ومسؤوليات جسام، بل إنه في موقع مهم للغاية

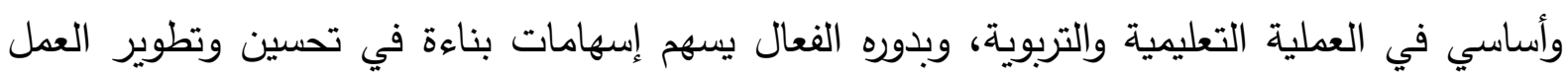

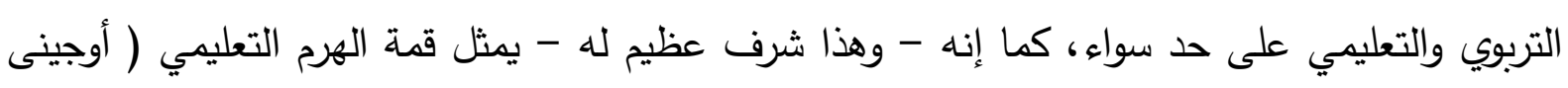

مدانات ، برزة كمال : 2002 ،9). ويعد الإثراف التربوي ضرورة حتمية ومن أهم الأسس والوسائل التى يتم الاعتماد عليها بشكل كامل فى

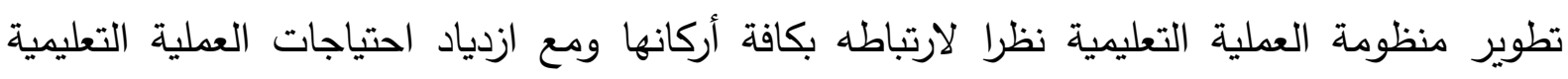

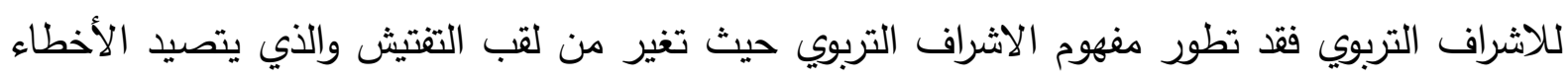

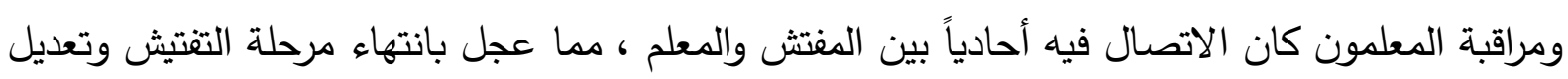

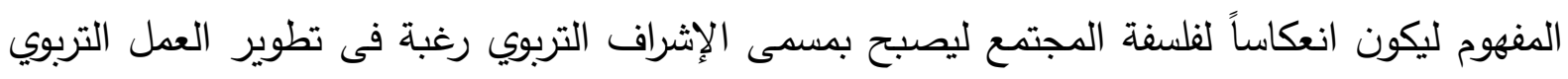


وتوثيق الصلة بالمعلم، وتقوية التفاعل بين المعلم والمشرف التربوي، وذلك بغرض تثخيص الموقف التعليمي وتحليله وتقويمه ومن ثم تحسينه وتطويره .

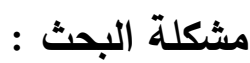

مع تغير مفهوم الإدارة المدرسية نتيجة للدراسات الإدارية و النفسية و التربوية ، أصبحت وسيلة لغاية هى

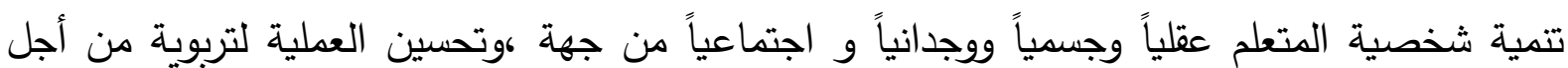
تحقيق هذه التمية وتوجيهها من جهة أخرى ، وتتمية المجتمع التى تعمل فيهم نو جهة ثالثة (أحمد وندانيا

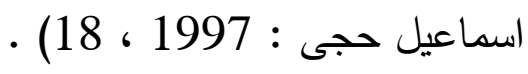

ونظراً لأهمية الاشراف التربوي فى توجيه وتتفيذ العملية التعليمية داخل وخارج المدرسة ، فإن المشرف

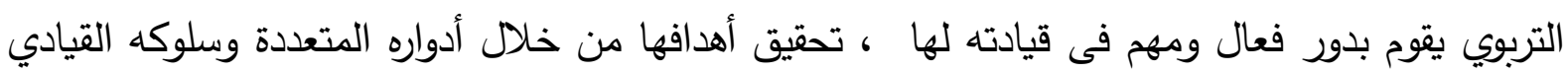

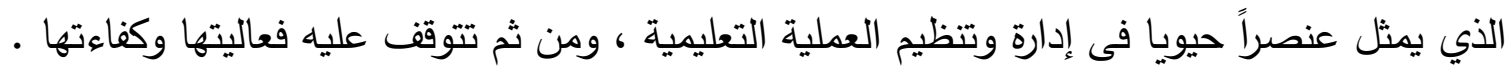
تساؤلات البحث :

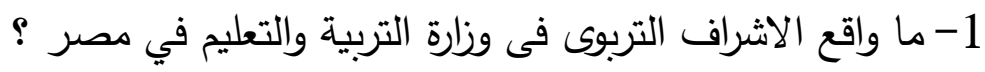

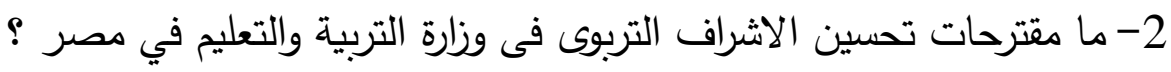

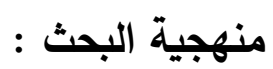
هذا البحث من البحوث النظرية المكتبية ، حيث يعتمد على معايثة الباحثة لمشروع البحث ومجموعة من

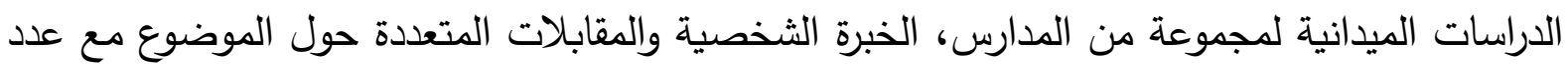

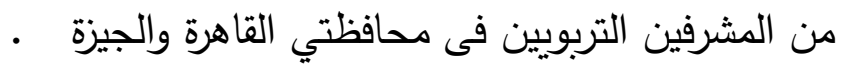

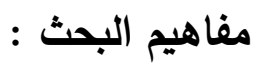
تعددت تعريفات الإشراف التربوى بسبب تعدد الفلسفات التربوية واتساع مجالات العمل الإشرافى وتعدد مهامه ووظائفه ، ومن هذه التعريفات :

1- تعريف ( خالد الثهرى : 2014، 10 منهده ) عملية فنية ، شورية ، قيادية ، انسانية، شاملة غايتها تقويم وتطوير العملية التعليمية والتربوية بكافه محاورها.

2- تعريف ( عبد الرحمن العبد الجبار :2008 ، 28 ) ) : جهود تربوية تطويرية وعملية قيادية وإدارية تهاف إلى تحسين عملية التعليم والتعلم ،وإن تتوعت فى أساليب ووسائل تحقيق هذا الهدف. 3- تعريف ( محمد بدر صيام : 2007 ، 43) بأنه عملية قيادية تعاونية تعنى بالنظام التعليمى بجميع

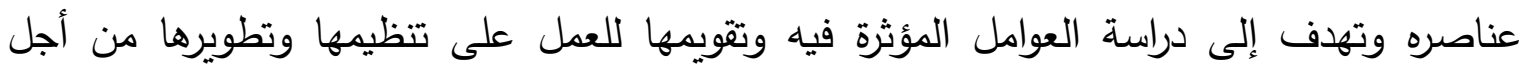
الارتقاء بمستوى الأداء فى النظام التعليمى بثكل عام وتحقيق الأهداف التربوية المنشودة .

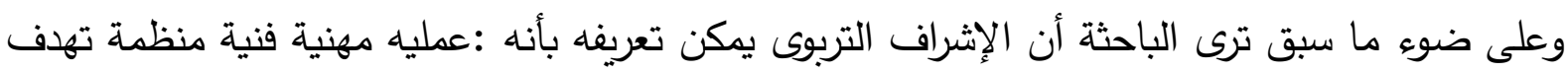

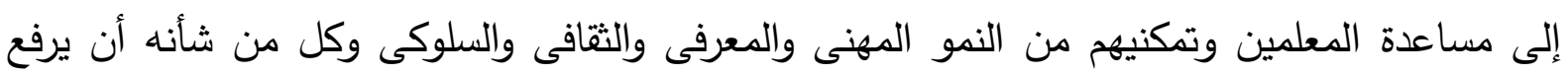
مستوى عملية التعليم والتعلم • 


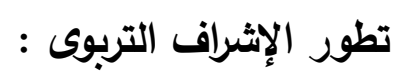

تطور مفهوم الإشراف التربوى من نظام التفتيش الذى يقوم على أساس مراقبة عمل المعلمين وتصيد أخطائهم إلى عملية التوجيه التى تقوم على أساس التعاون بين المشرفين التربويين والمعلمين من أجل

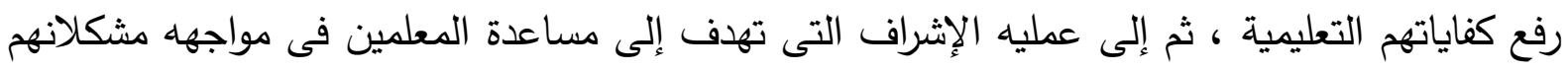

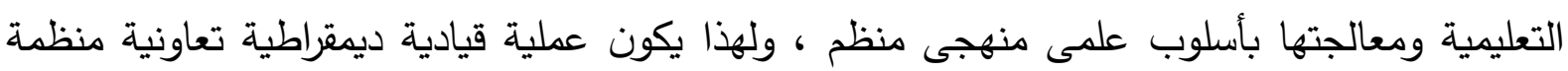

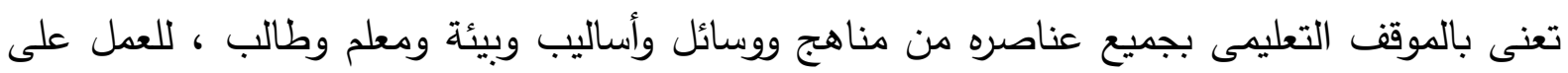

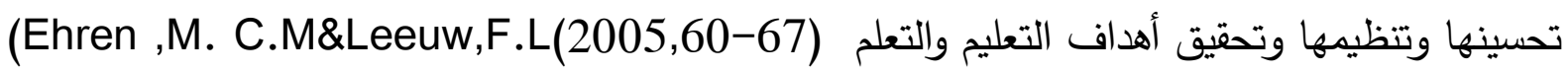
ومن خلال استعراض وجهات النظر المتعددة للتطور التاريخى لمفهوم الإشراف التربوى فإننا يمكننا تلخيص الإشراف التربوى فى المراحل الأساسية الثلاث الاتية :

أولاً: مرحلة التفتيش:

بدأت هذه المرحلة من القرن الثامن عشر حتى أوائل الثلاثينيات من القرن العشرين ( عاهد المقيد :

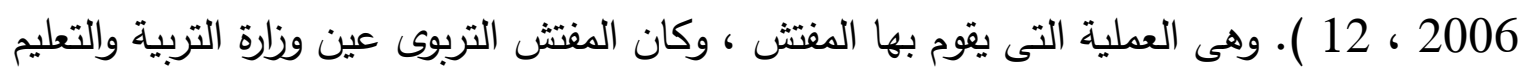

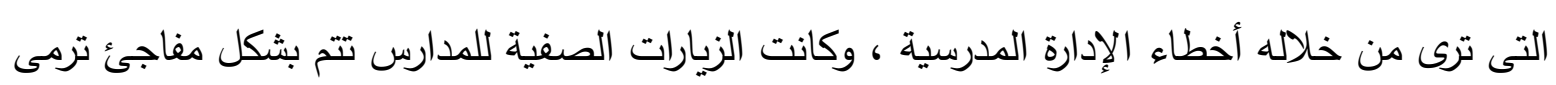

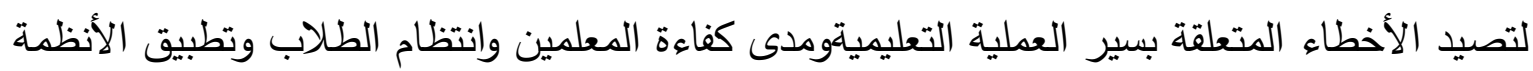

$$
\text { واللوائح (عماد محمد إبراهيم : } 2012 \text { ، } 3 \text { ) ) . }
$$

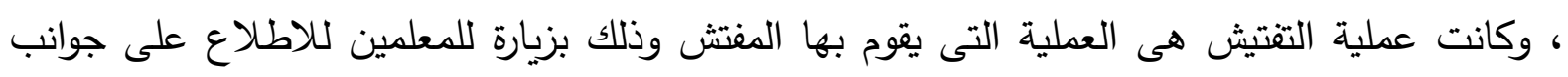
القصور ونقاط الضعف لديهم ومن ثم تقويمها ومحاسبتهم عن الأخطاء والنواقص والهفوات التى يحددها خلال زيارته ، فمهيته هى الكثف عن نقاط الضعف لدى المعلمين وتصيد الاخطاء من خلال زيارة

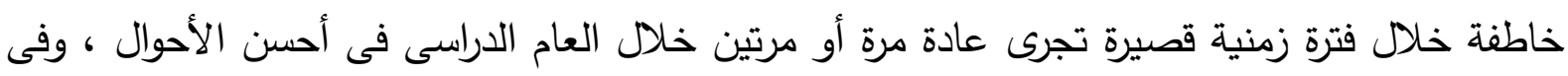

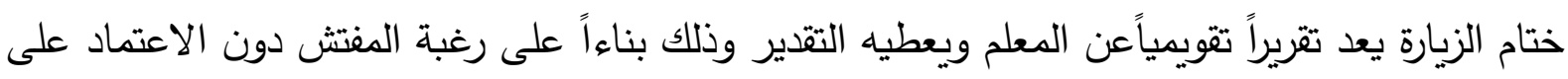

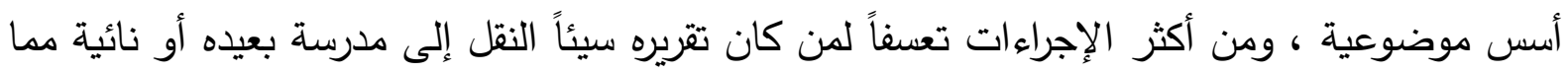

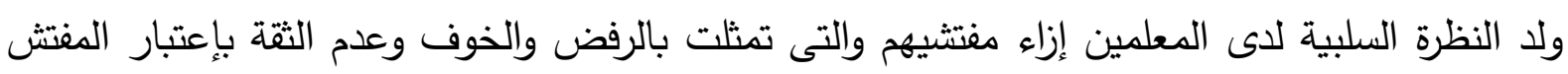

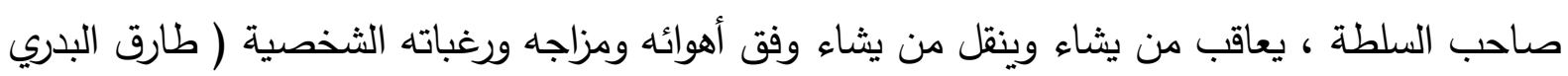

. 15 ، 2001 :

ثانياً مرحلة التوجيه :

ظهرت مرحلة التوجيه التربوى نتيجة التقدم فى علم التربية والعلوم الاجتماعية الأخرى المساندة لها

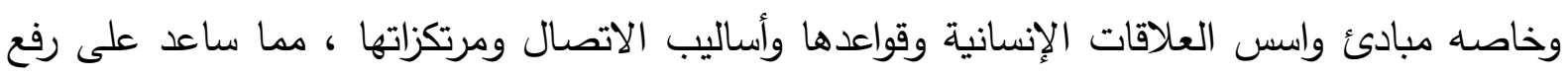

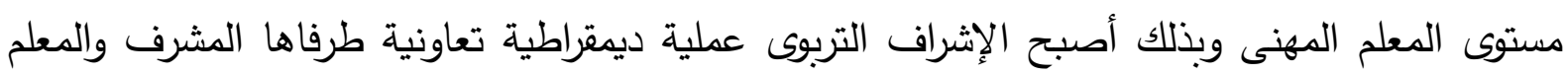
وحل المشاكل التى يواجهها المعلم ورفض التسلط والفرض ويحترم الاختلاف فى الرأى ويعترف بالقيمة الحقيقية للاجتهاد، إن عملية التغيير والتطور فى مفهوم الإشراف التربوى لم تكن سهله لسببين أولهما : 
أن تغير السلوك والممارسات بصورة عامه عملية صعبة وتزداد صعوبتها بالنسبة للأشخاص الذين مارسوا هذا السلوك لفترة طويلة وهذا ما ينطبق على المفتشين الذين أصبحوا موجهين ، والسبب الثانى :

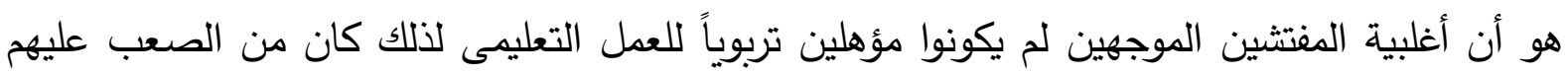
الانتقال من مفهوم وأسلوب التفتيش إلى اسلوب التوجيه حيث أن هدف التعليم عندهم هو تطوير المعرفة

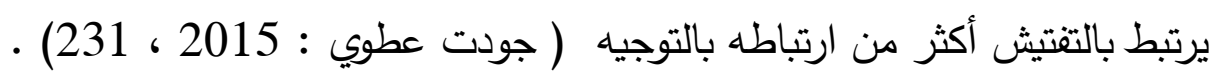

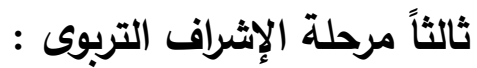
فى هذه المرحلة استبدل مصطلح التوجيه التربوى بالإشراف التربوى لأن الإشراف أهم واشمل والتوجيه جزء منه ولقد تطور مفهوم الإثراف التربوى بسبب التطورات السريعة فى الفكر التربوى فأصبح عملية التبدية

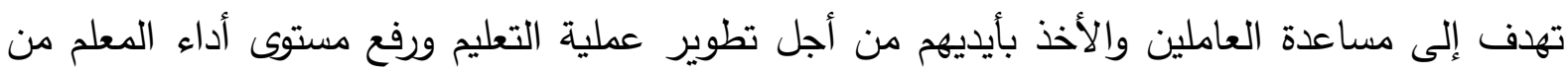
خلال برنامج مخطط قائم على التعاون والثورى بين المعلمين والمشرفين ( رافدة الحريرى : 2006 ، 14

ونجد أن الهدف الرئيسى لهذه المرحلة هو تحسين العملية التعليمية فهو أشمل وأوسع لأنه يهتم بالموقف

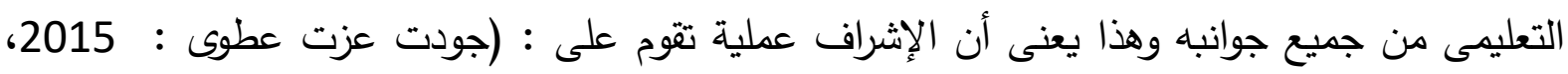

1- تقوم على الدراسة والاستقصاء بدلا من التفتيش.

2- تشمل جميع عناصر العملية التربوية من مناهج ووسائل ومعلم ومتعلم وبيئة بدلا من التركيز

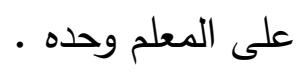

3- تستعين بوسائل ونشاطات متتوعه بدلا من الاقتصار على الزيارات والتقارير •

4- تقوم على التخطيط والتتييم التعاونى العلمى بدلا من التركيز على الجها الفردى .

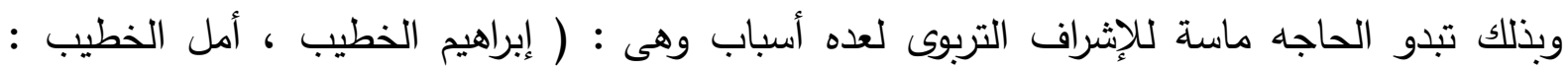

1- تحسين العملية التعليمية لتحقيق التعلم فى عصر انفجار المعرفة .

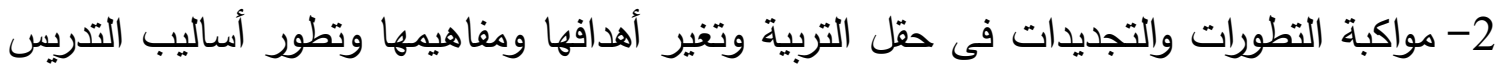

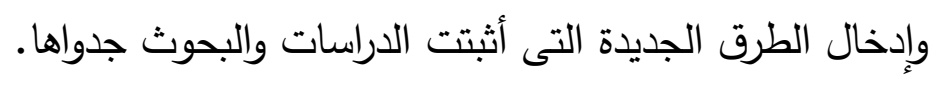

3- الأخذ بيد المعلمين وخاصه حديثى العهد فى التعليم وتبصيرهم بأحدث أساليب التربية ووسائل

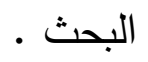

4- مساعده المعلم القديم على تطوير نفسه وتحديث اساليبه وتعزيز قدراته . 5- حماية التلاميذ من المعلمين الجدد وغير المؤهلين •

ويبنى الإشراف التربوى فى مرحلة الإثراف التربوى على الأسس التالية كما أوردها: ( جودت عطوي الجيد : 
1- احترام الذات وقبول الفروق الفردية وإعطاء حرية التعبير عن الذات .

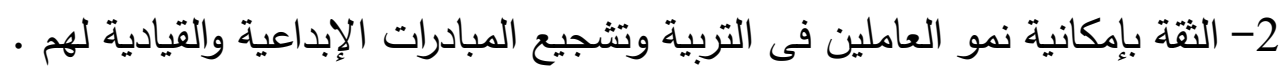

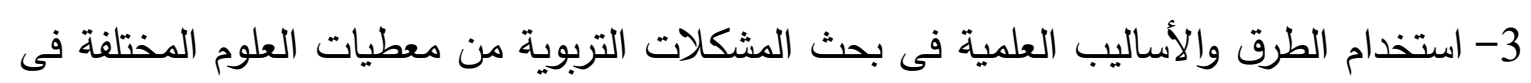

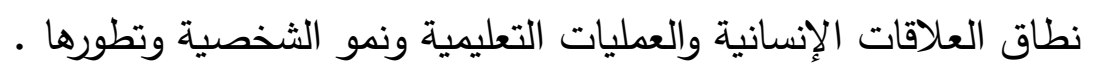

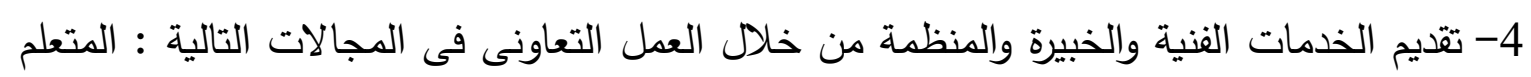

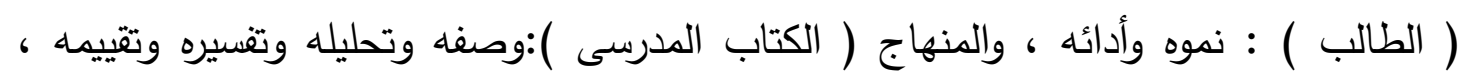

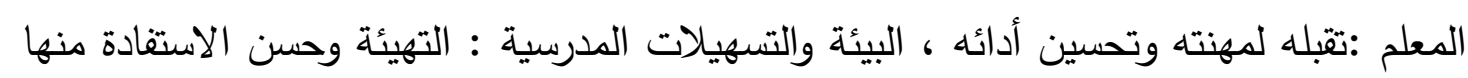

$$
\text { وتقترح الباحثة مجموعة من الأهداف المتعقة بالإشراف التربوى كما يلى : }
$$

1- تحسين العملية التربوية وعمليتى التعليم والتعلم من خلال القيادات المهنية والمدراء والمعلمين .

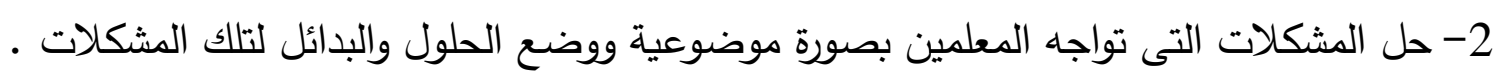

$$
\text { 3- تطوير المناهج الدراسية باستمرار لمواكبه التقدم التكنولوجى . }
$$

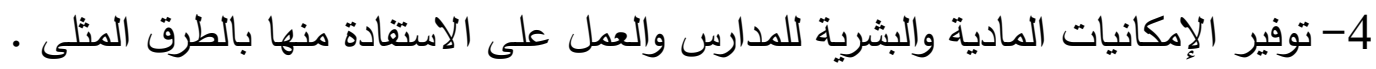

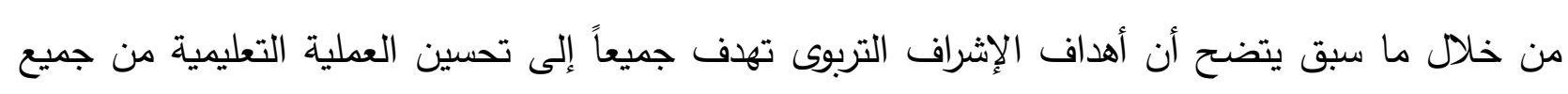

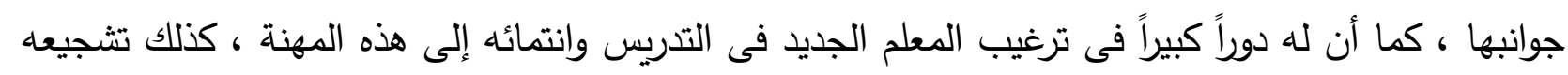

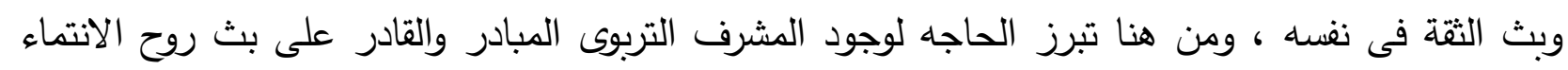

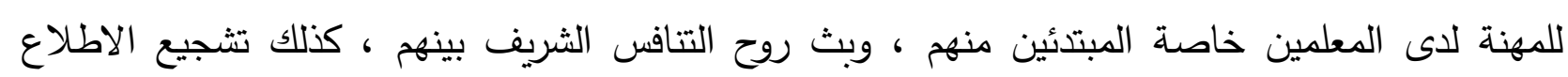

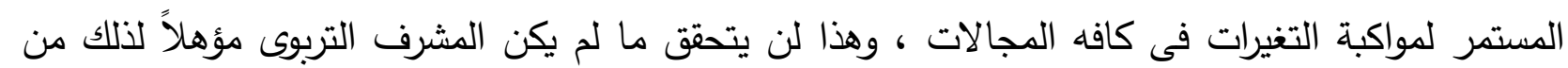

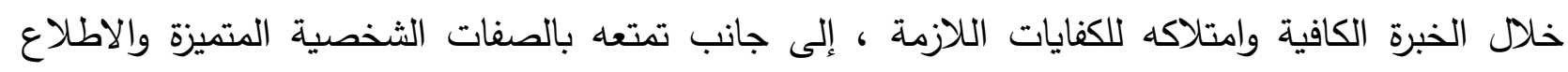
الواسع وقدرته على الإقناع وكسب ثقية واحترام الآخرين خصائص الإشراف التربوى :

أثار كل من إبراهيم الخطيب وأمل الخطيب (2003، 35-36) إلي بعض خصائص الإشراف التربوى كالتالي :

1 - عملية ديمقراطية منظمة ، ترتكز على التعاون والاحترام المتبادل بين المعلم والمشرف التربوى .

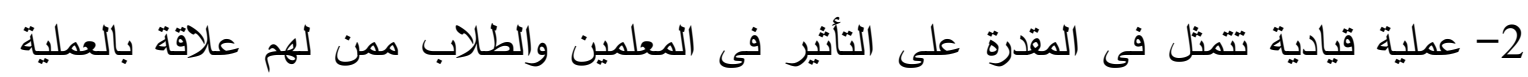

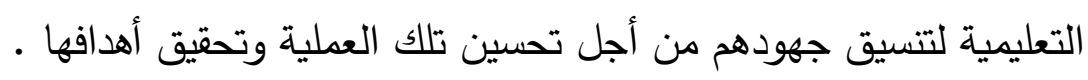

3- عملية شاملة ، تعنى بجميع العوامل المؤثرة فى تحسين العملية التعليمية وتطويرها ضمن

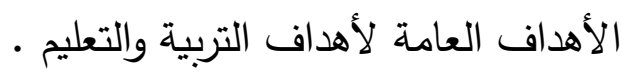


4- عملية إنسانية ، فالإشراف يهتم بالعلاقات الإنسانية ورغبات وميول العاملين معاه ، وإيجاد جو

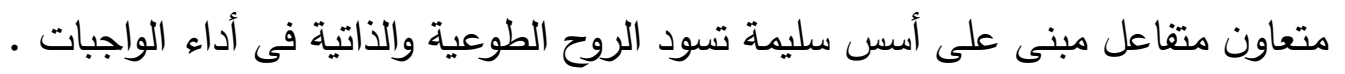
5- عملية تعتمد على الدراسة والبحث والتجريب ، وتوظيف نتائجها لتحسين التعلم ، وتقوم على التى السعى لتحقيق أهداف واضحه قابلة للملاحظة والقياس أحيانا .

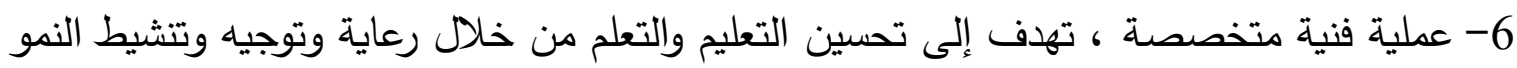
المستمر لكل من المعلم والطالب والمشرف نفسه ، وأى شخص أخر له له دور فى تحسين العئ العملية التعليمية التعلمية .

7- عملية ديناميكية مرنة منطورة ، لا تعتمد أسلوباً واحدا ، وإنما تعتمد أساليب متعددة .

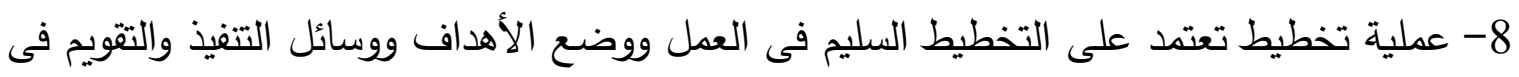
فترة زمنية محددة .

9- عملية تدريب المعلمين ورفع مستوى كفاياتهم ومهارتهم وفق الحاجات التى تناسب كل معلم . 10- عملية تعاونية ، تحرص على إثراك المشرفين والمدربين والمعلمين والطلاب وأولياء الأمور فى التخطيط والتتفيذ والتقويم ، وذلك بتتسيق جهودهم وتتظيمها ، أى العمل من خلال الجماعة .

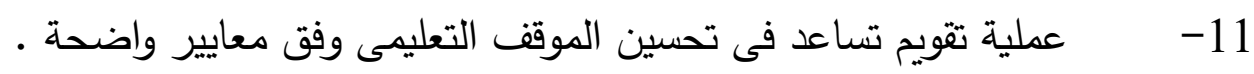

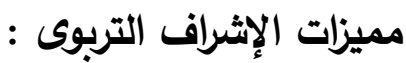

يتميز الإثراف التزبوى الحديث بالعديد من المميزات الهامة منها كما ورد : (حسن الطعانى : 2005،

1-شمولية الأشراف التربوى بحيث يشتمل على جميع مجالات العملية التربوية من مدخلات

$$
\text { ومخرجات وتغذية راجعة . }
$$

$$
\text { 2- استمرارية الإثراف التربوى على مدار العام • }
$$

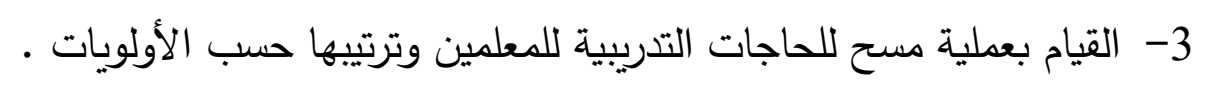

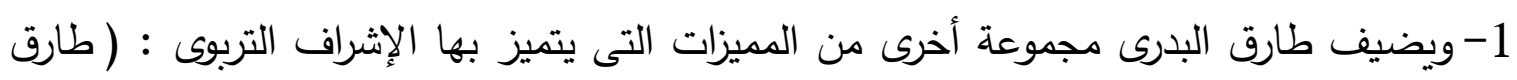

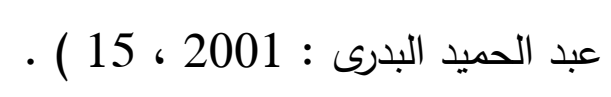

1- أنها عملية ديمقراطية تعاونية منظمة تقوم على أسس التخطيط العلمى والاستقصاء والتحليل

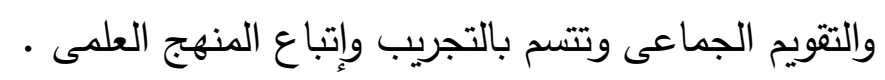

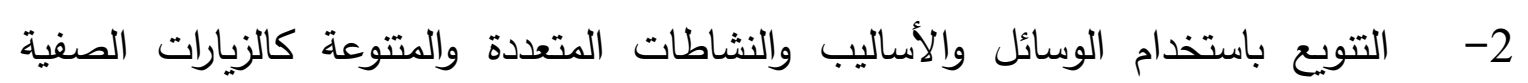

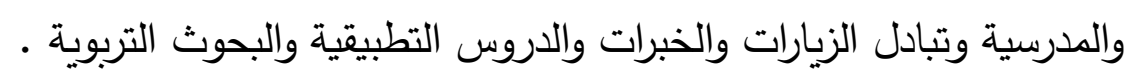

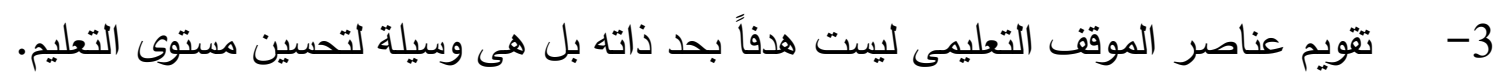

4- ت تصف بالإيجابية والعمق التين تعتمدان على نموذج التواصل المفتوح فى حوار المشرفين

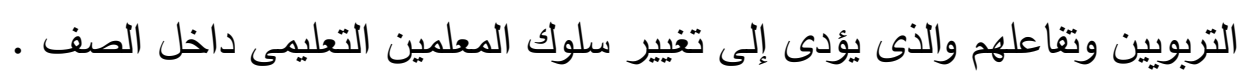


ويذكر البستان واخرون أن الإشراف التربوى مهم جداً وخاصة بالنسبة للمعلمين وذلك للأسباب

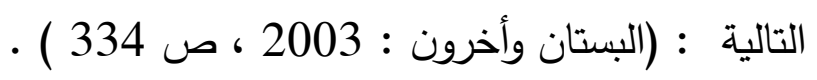

1- إن عدد لابأس به من المعلمين يبدأون الخدمة دون إعداد مهنى كاف فإن هؤن إلاء بأشد الحاجه

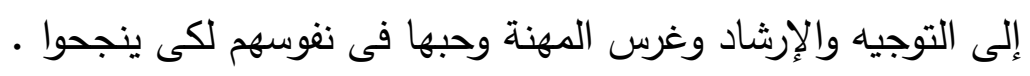

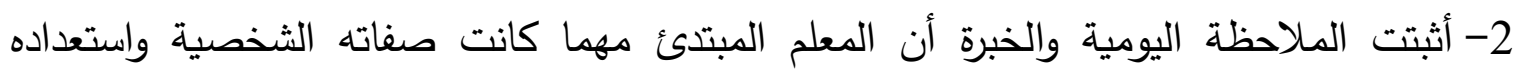

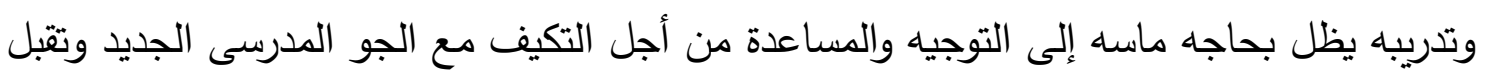

$$
\text { العمل بجميع أبعاده ومسئولياته . }
$$

3- الإثراف التزبوى ضرورى أيضا للمعلم القديم الذى لم يتدرب على الاتجاهات المعاصرة والطرق

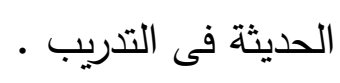

4- المعلم المتميز يحتاج أيضا للتوجيه والإرشاد لاسيما عند تطبيق أفكار جديدة .

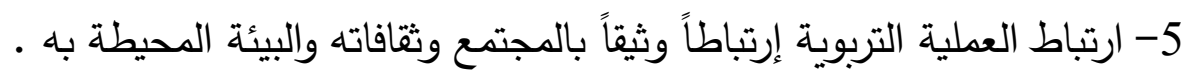

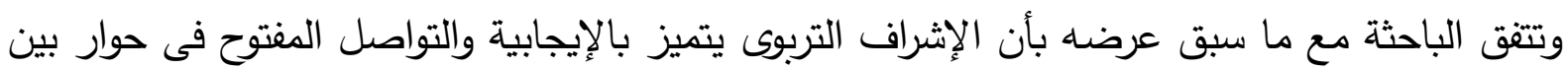

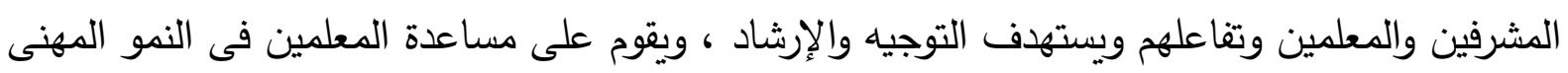

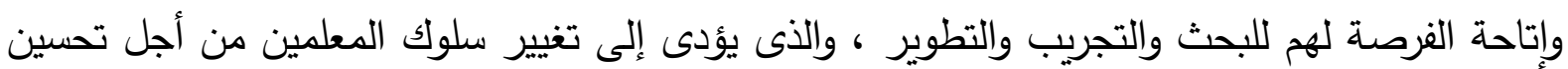
وتطوير العملية التعليمية ، وهو خدمة تربوية تهتم بكل ما يؤثر فى عملية التربية والتعليم. المبادئ التى يقوم عليها الإثراف التربوى : يستند العمل التربوى بصورة رئيسية على مجموعة من الاختصاصين الذين يتعاونون ويتفاعلون معاً

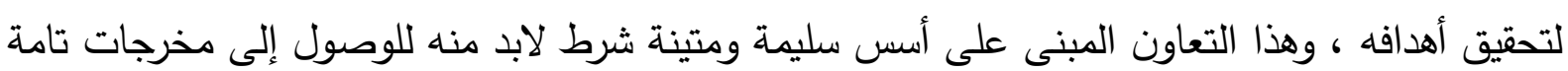

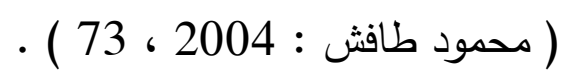

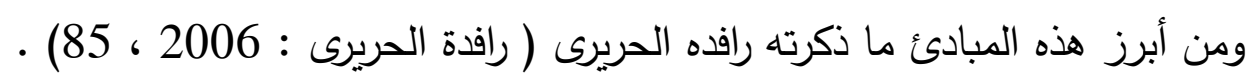

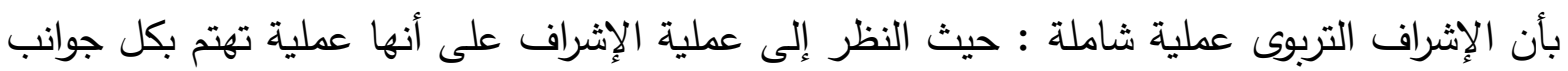

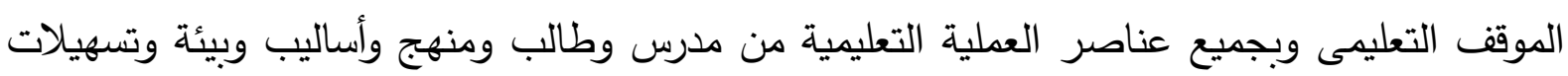
مدرسية والعمل على تحسينها وافرتقاء بمستواها ـ

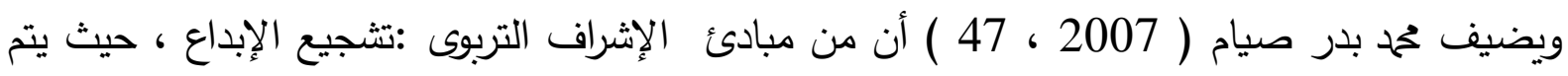

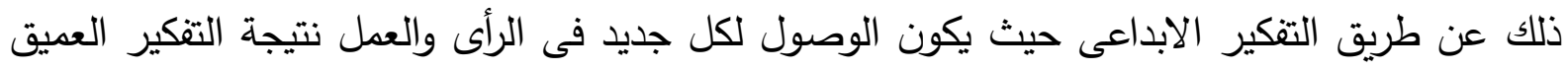

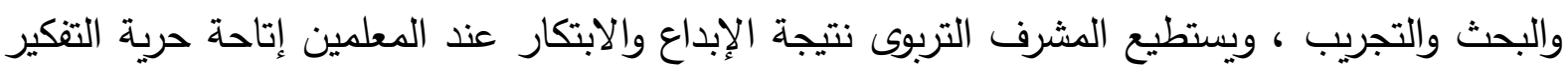

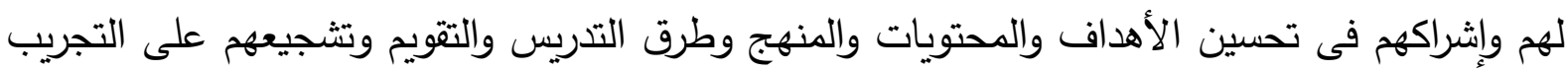
وبث الثقة بالنفس والاعتراف بجهودهم والإيمان بقدراتهم. 
ويذكر كل من إبراهيم الخطيب وأمل الخطيب (2003، 35-36) أن الإشراف التربوى :عملية تعاونية :

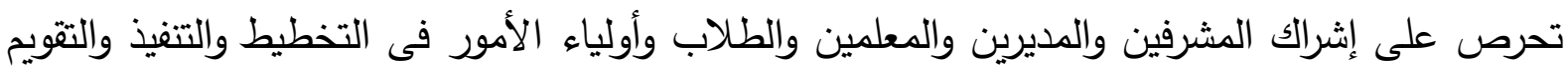
والتقويم ، وذلك بتتسيق جهودهم وتتظيمها أى العمل من خلال الجماعة . ومن خلال استعراض أراء الباحثين والمربين حول مبادئ الإثراف التزبوى يلاحظ أنه من أهم المبادئ التى يرتكز عليها الاشراف التربوى هو : 1- عملية منظمة وموضوعية بعيدة عن الأهواء والتحيز الثخصى ومخططة وهى عملية مبنية على قواعد علمية ومنطقية تهاف ‘لى تطوير عملية التعليم والتعلم وتثجع على الإبداع والابتكار

$$
\text { والنمو المستمر لجميع العاملين فى منظومة الإثراف التربوى . }
$$

2- عملية بها استثراف للمستقبل .

3- عملية علمية وشاملة ومرنة.

4- عمليه ديمقراطية بحيث يسح بتبادل الآراء والأفكار وتقديم الاقتراحات المناسبة لحل المشكلات

وتقديم البدائل لتطوير وتحسين العملية التعليمية التعلمية . 5- عملية فنية وتثجع على الإبداع والابتكار .

الإشراف التربوي الواقع و المأمول :

لو أمعنا النظر في مسيرة الإشراف التربوي منذ انطلاقته كمصطلح بعد مصطلح التوجيه ودققنا ملياً في المرحلة الانتقالية لما يمارس في الميدان التربوي قبل الإشراف من قبل الموجهة التربوية لوجدنا أن

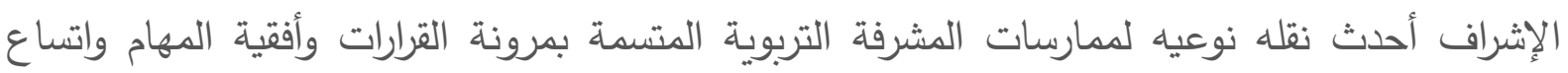

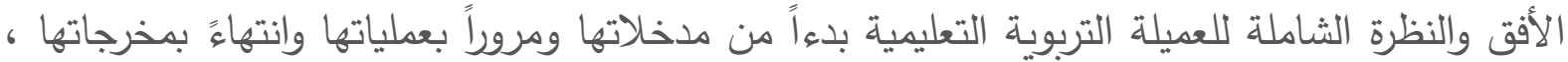
ولكن لو سألنا أنفسنا من باب التقويم للمهام الاشرافية التي ننفذها ،هل حققت النقائة النقة النوعية في ممارسات المشرفة قفزة في تغيير وجه الواقع بميداننا التربوي وبمعنى أدق هل كان للإثراف التربوي أثره البارز في

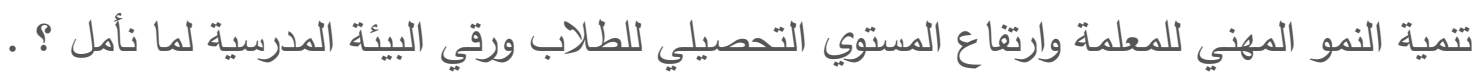
قد لا يمر يوم دون أن ترتفع أصوات المشرفين التربويين بالثكوى من كثرة الأعباء والمهام والتكاليف

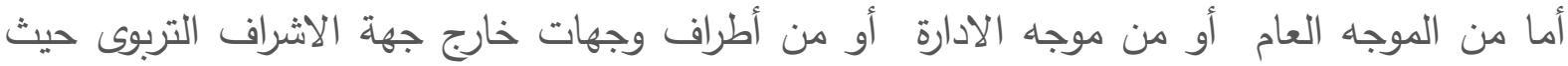
يكلف المشرف التربوى من هذه الجهات بأعمال الأولى أن تتفذها هذه الجهة ، مثل متابعه المدرسة كلها

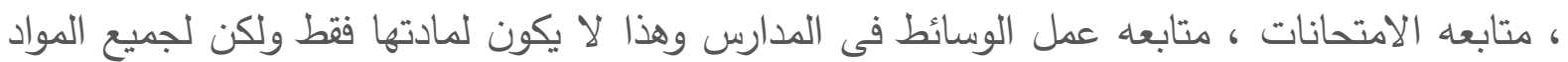

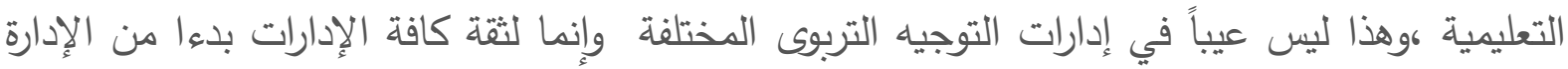
المركزية بقدرات المشرفيين التربويين و ارتباطها المباشر بالميدان التربوي. 
والحقيقة أن المشرف التربوى يواجه في عمله الإثرافي مشقة أيما مشقة تقع على كاهله ؛ فهو من جهة مطالب بتتفيذ الأعمال المكلفة بها في موعدها ومن جهة أخرى مطالب بالتغيير والتطوير المنوط بها كقائد للتطوير بالميدان التربوي ،حتى احتار في تصنيف الأوليات واحتار ما بين المهم والأكثر أهمية - وبأيهما تبدأ- وبين معدعة الأعباء وتعدد المسؤوليات وتتوع المهام تولد لديه هذه الحيرة تشتتاً فكرياً لا يقبل الربط ، حتى أصبح المشرف التربوي يدور في دوامة ما بين مطالب رؤسائه ذات الطابع النظري المتصفة بالمثالية وبين احتياج الميدان التربوي وتراكماته التي تتطلب إعادة في بنيته التحتية

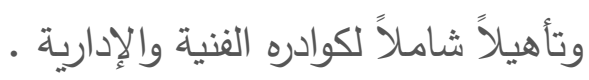

فهل تستطيع المشرف التربوى أن ينجز أو تحدث شيئا من التغيير ؟ من هذا المنطلق كان ولابد من تضافر الجهود من قبل المعنيين بالتغيير والتطوير بدءاً من صانعي القرار ومروراً بالقيادات التربوية. ومع تضافر الجهود لابد من توصيف و تحديد عل المشرفة التربوية ذات الطابع الفني البحت على ملى حسب معطيات واقع الإشراف التربوي. حينها سيبرز دور المشرفة التربوية من خلال مساهمتها الفاعلة

$$
\begin{aligned}
& \text { في التحسين والتطوير • } \\
& \text { معوقات الإشراف التربوي : } \\
& \text { أولا : المعوقات الإداريةية: }
\end{aligned}
$$

1 - كثرة الأعباء الإدارية على المشرف التربوي :

العملية التربوية عملية معقدة ومتشابكة ومتعددة الجوانب تحتاج إلى وقت وجهد وإخلاص ، ومع هذا يكلف المشرف التربوي بزيارة عدد من المعلمين يفوق النصاب المقرر وأحيانا يصل إلى الضعف ومع هذا يسند إليه أعمال إدارية تحد من نشاطها الميداني وربما تؤجل خطته بسببها مما يؤثر على عطائه ونشاطه في إعداد النشرات والندوات والبرامج التدريبية والمتابعة الفعلية لمهامها الأساسية.

2- قلة الدورات التدرببية للمشرف التربوى و المتعلقة بالمهام الأساسية المنوط بها: التدريب على المهام الأساسية للمشرفة كالتخطيط و التدريب و التقويم هام جدا و كذلك التدريب على تطوير القدرات الشخصية و على كل ما يستجد في الميدان التربوي. 3- ضعف قدرة بعض مديرين المدارس واعتمادهم على المشرف التربوي : الإدارة المدرسية قيادة تربوية تنفيذية واشرافية وعليها من المسئوليات ما يجعلها تحتاج إلى كفايات تربوية متميزة إلا أن بعض هذه الإدارات تثكو من ضعف إما في القدرة على الإشراف والمتابعة والتقويم وإما 
في القدرة العلمية والتربوية و إما في حل مشاكل المعلمات وقد تكون إدارة متزمتة أو مهملة وبالتالي ينعكس ذلك سلبا على كل عناصر العملية التربوية في الددرسة و يزيد من أعباء المشرفة التربوية. 4- قلة أعداد المشرفيين التربويين نسبة لعدد المعلمين 5- غياب معايير اختيار المعلمين بناء على الكفاءة العلمية و التربوية ، فتجد المشرف التربوي نفسه عاجز عن التطوير أو التحسين لانعدام الكفاءة. 6- تكليف المعلمين والمعلمات بمهام إدارية. 7- عدم توفر الأماكن اللازمة لعقد الاجتماعات والبرامج التدريبية في المدرسة و قلة عددها في مراكز

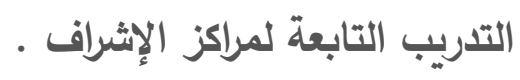
8- قصور التعاون بين المشرف التربوى ومدير المدرسة . 9- تذمر بعض المديرين من التحاق المعلمات والمعلمين بدورات تدريبية . 12- عدم كفاية الوسائل اللازمة لرصد نشاطات الزيارات الصفية ، فعلى المشرف أن يجتهد في إعداد

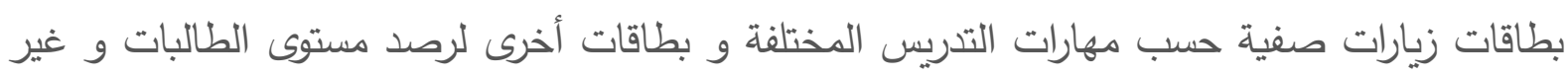
ذلك.

13- ضعف الوعي بمسئولية العمل لاى بعض المشرف التربوى والمديرين والمعلمين . ثانيا : المعوقات الاقتصادية 1. قلة توفر الوسائل التعليمية اللازمة لعمليتي التعليم والتعلم و عدم توفر التقنيات الحديثة للتدريس. 2. قلة وجود حوافز مادية للمشرفيين التربويين وللمعلمات. 3- قلة توافر المكتبات ( أو قلة الكتب و المراجع العلمية والتربوية ) في المدارس. ثالثا : المعوقات الفنية 1. ضعف الممارسات التعليمية الصفية ( عدم الإلمام بطرق التدريس و أساليب التقويم ) التي تعاني

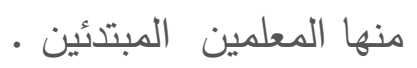
2. الممارسات الخاطئة السائدة في برامج الإثراف التربوي بأساليبها وطرقها وأدواتها ، وما ينشأ عنها من علاقات سلبية بين أطراف العملية الاشرافية. 
3. تلاحق أو تتابع النظريات و الابحاث التعليمية التعلمية والتجديدات التربوية وكثرتها كماً ونوعاً وعدم توفر خطط اشرافية فنية تحدد طرق الاستفادة منها و تساهم في تطوير الاتجاه الإيجابي لأى المعلمين

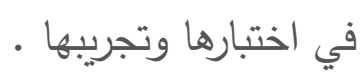

4. مقاومة المعلمين وخاصة الذين لايهم خبرة طويلة في التدريس للتغيير في تقبل الأفكار التطويرية وفثل بعض الممارسات الاشرافية القائعة على إدارة التغيير وتسويقه بصورة منتجة لدى هذه الفئة من - المعلمات

5. عدم تتفيذ بعض المعلمين لتوجيهات المشرف التربوى .

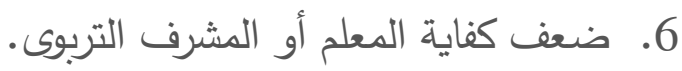
7. ضعف انتماء المعلمأو المشرف التربوى إلى المهنة. 8. ازدحام الفصول الدراسية . 9. عدم مشاركة المعلمين في التخطيط التربوي .

10. ضعف النمو المهني للمعلمين يث أن بعضهم يحتاجون إلى صبر وقيادة تربوية متأنية وحازمة

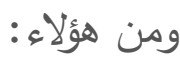
أ- المعلم الذى يعزف عن العمل رغبة في الراحة وإيثارا له على العمل ( كثرة الإجازات والغياب والأعذار ). ب- المعلم الذى يقف عند حد معين لا يتجاوزه لاعتقاده أنه بلغ القمة و التي تثتكي دائما و تتذمر من التدريس. ( ضعف الدافعية ) ج- المعلم الذى يرفض وجه نظر الآخرين فلا يستفيد منهم ولا يستثير ولا يقبل المشورة. 11. صعوبة المقررات الدراسية و عدم مواكبة معظمها للطرق الحديثة في التدريس. 12. عدم دقة أساليب التقويم التربوي الممارس من قبل المعلم أو المشرف. رابعا : المعوقات الثخصية 1. عدم قدرة بعض المشرفين والمديرين على إتباع الأساليب القيادية المناسبة. 2. ضعف العلاقة بين كل من المشرفين والمديرين والمعلمين 3- ظهور بعض المشاكل الثخصية وتأثيرها على العمل أحيانا. 
من خلال تحليل واقع الإثراف التربوي نجد إن الأسباب التي تدعو إلى تطوير مهام المشرفة التربوية كثيرة و يمكن تحديد الجوانب التي يجب أن نهتم بتطويرها كالآتي:

أولا: التخطيط

إن حاجة المشرف التزبوى إلي التخطيط أمر ضروري ومهم ويضمن استمرارية العمل علي الوجه الصحيح

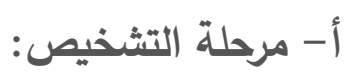

وتثمل هذه المرحلة : تحليل نقاط القوة والضعف في الأساليب والممارسات المستخدمة حالياً في التدريس في كل مدرسة تشرف عليها؛ وتحديد وتحليل المجالات التي يجب إجراء تغيير عليها مع الأخذ بعين الاعتبار سمات تعليم المستقبل ومتطلباته.

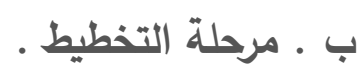

وتثمل هذه المرحلة : تحديد الأهداف، وتحديد الخطط الإجرائية المطلوبة ، وتحديد الأنشطة الداعمة لتحقيق الأهداف المتعلقة بتحقيق سمات ومتطلبات تعليم المستقبل.

ج · مرحلة التنفيذ.

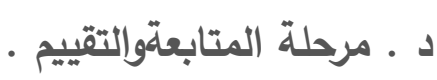
خصائص التخطيط التربوي الفاعل:

1. التعاون الايجابي بين المشرف التربوى و المعلين و المديرين و تكوين فرق عمل لتنفيذ الخطط. 2. التجريب العلمي : تجريب المشرفات والمعلمات أساليب وطرائق جديدة في العمل للوصول إلى نتائج

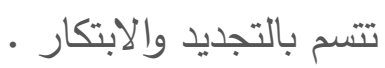

3. التفكير الجماعي والتفكير التعاوني يضاعف القدرة على حل المشكلات ويجعل الحلول التي يتت الوصول إليها أكثر قبولاً وثباتاً .

4. المرونة وملاءمة الظروف المتغيرة بحيث تضطر المشرفة أحيانا لإجراء تعديلات في خطتها

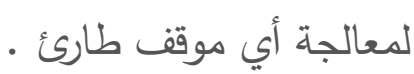


5. التجديد والابتكار من أجل تحقيق التطوير في العملية التعليمية التعلية وتطوير المقرات التعليمية وطرائق تدريسها والوسائل المعينة وتتنيات التعليم الحديثة وأساليب توظيفها من خلال البح البحث المتواصل

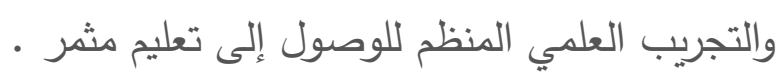

6. استشراف المستقبل : فمن خلال خبرة المشرف التربوى فيمكنها الإبداع من خلال دراسته العلمية والقدرة على توقع المشكلات والصعوبات واتخاذ الإجراءات الوقائية التي تمكنه من تلافي المشكلات التي من المكن أن تعيق تتفيذ الخطة.

ثانيا: التدريب:

المدرسة هي البيئة التي تحدث فيها عملية التعليم و التعلم و هي البيئة التي تمارس فيها المعلمة دورها

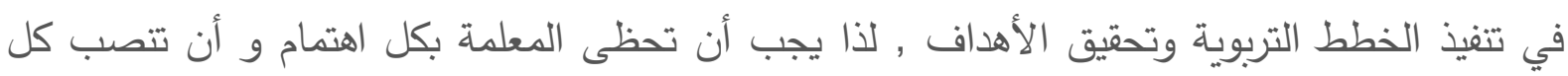
الجهود لتطوير أدائها و لتحسينه. أنواع التدريب:

1- البرامج التدريبية التأهيلية ( إكساب المعلمين المستجدات والمهارات و المعارف الأساسية اللازمة

للأداء المتقن)

2- البرامج التدريبية العلاجية ( معالجة النقص أو القصور الذي يظهر على البعض ).

3- البرامج التدريبية الاثرائية ( تطوير أداء المعلمين بناء على المستجدات و المتغيرات في مجال

التربية والتعليم ).

4- البرامج التدريبية التحويلية ( تدريب المعلمين على مهام جديدة لكى يقوموا بها مثل ترشيح

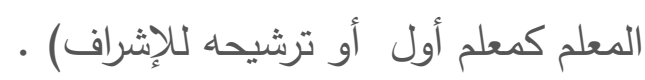

5- البرامج التدريبية الإجرائية ( البرامج التدريبية التي ترتكز على التدريب القائم على إجراء البحوث

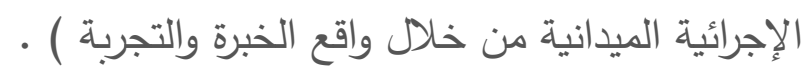

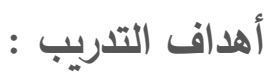
مما سبق يمكن تصنيف الأهداف التي يرمي التدريب إلى تحقيقها في ثلاث مجموعات رئيسة هي : أ ـ أهداف تقليدية : وتتضمن أهدافا معروفة مثل : 1 - تدريب المعلمين الجدد وتقديم المساعدات اللازمة لهم • 
2 - إعداد برامج توجيهية تهدف إلى تزويد المعلين و المعلمات بمعلومات ، ومهارات معينة ، عند إدخال تعديلات على أسلوب العمل . 3 - إعداد برامج توجيهية تساعد المرشحين لوظائف اشرافية أعلى على الإلمام بمهام الوظائف الجديدة. ب ـ أهداف حل المشكلات : تدريب المعلمين و المعلمات ليكونوا قادرين على التعامل مع المشكلات الميدانية وفق أساليب علمية متطورة ، تحتاج إلى قدرة ومهارة في التشخيص والتحليل ، وإجراء

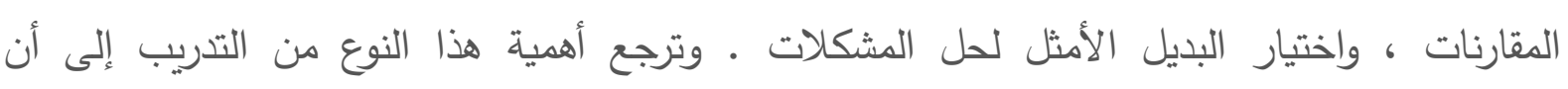

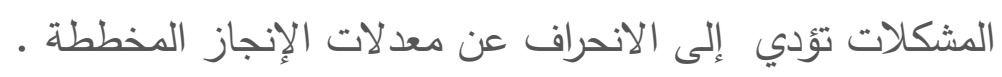
ج ـ أهداف إبداعية : تمثل مستوى أعلى من المهمات التدريبية ، وتعتمد على استخدام أسـاليب علمية

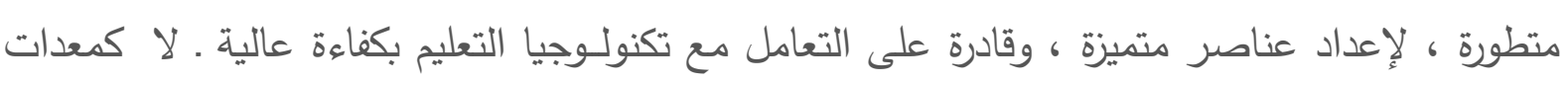

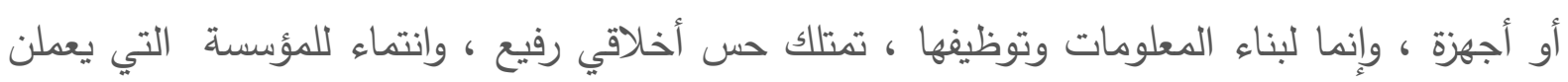

ثالثا : المتابعة وإلتقويم

بناء أدوات تقييم جديدة تهدف إلى تطوير الأداء ، تقوم على توظيف التيقيم القائم على الأداء والتقييم الذاتي وتقييم الرفاق بعضهن لبعض داخل المدرسة بالأسلوب الذي يمكن أن يسمى (إثراف توفي الرفاق).

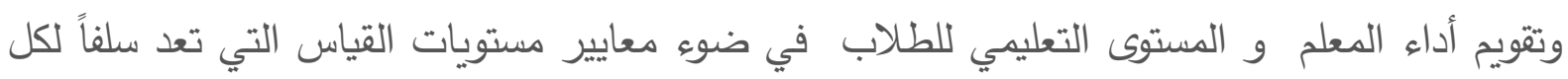

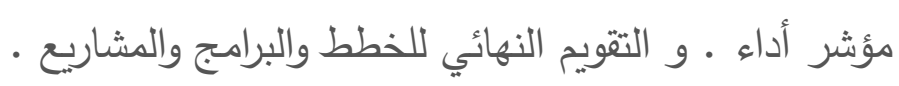
دور الإثراف التربوي على ضوء اللائحة الجديدة للأداء الوظيفي فى الكادر :

$$
\begin{aligned}
& \text { 1- تثاركي ( من الفردية إلى التثاركية ). }
\end{aligned}
$$

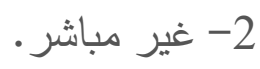

$$
\begin{aligned}
& \text { 3- أقل تحكما } \\
& \text { 4- } \\
& \text { 5- قائم على الأنشطة / البرامج / المشاريع. }
\end{aligned}
$$

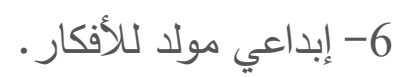

$$
\begin{aligned}
& \text { 7- قائم على البحث والتجريب. }
\end{aligned}
$$

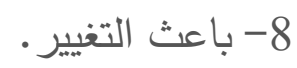

$$
\begin{aligned}
& \text { 9- استراتيجي التخطيط. } \\
& \text { القيادة بالمشاركة والعمل الجماعي بروح الفريق. }
\end{aligned}
$$




$$
\begin{aligned}
& \text { 11- انعكاسي ( معلم مستقل ييسر عمله إشراف غير مباشر) } \\
& \text { 12 } \\
& \text { 13- حواري ( من تقديم التعليمات إلى الحوار). } \\
& \text { 14- الإشراف بأسلوب القبعات الست . } \\
& \text { 15- - داعم ( من التقييم إلى الدعم) }
\end{aligned}
$$

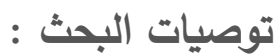

1. تخفيف الأعباء الموكلة إلى المشرف التزبوي وتغريغه لعمل الإثراف.

2. الانتقال من الزيارة الصفية إلى الإثراف القائم على الأنثطة بحيث تصبح الزيارة الصفية وسيلة لتشخيص وقياس اثر التدريب.

3. قياس الإنجاز بالكيف وليس بالكم ( بدلا من : كم عدد الزيارات الصفية - كم عدد الزيارات الميدانية - كم عدد الأنشطة التي نفذت؟ يقيم الإنجاز من خلال تنفيذ أنشطة وبرامج الخطط التربوية و مدى تحقق أهدافها على المدى القصير و الطويل). 4. إعداد خطة لكل مدرسة حسب احتياجات المعلمين والطلاب. 5. تخفيف الأعباء الموكلة إلى المعلمين والنظر في نصاب المعلم.

6. إقامة برامج تدريبية طويلة وقصيرة المدى للمشرفات لتوعيتهن بمهام عملهن وأساليب تتفيذها ثم المتابعة بتأني وتدريبهن من خلال المواقف التي تقابلهن.

7. التشجيع على إعداد البحوث التربوية للمشكلات الميدانية ( مشرفيين و معلمين ) ووضع حوافز لذلك.

8. الحد من اكتظاظ الصفوف الدراسية حتى يستطيع المعلم تحقيق أهداف عملية التعلم والتعليم . 9. ضرورة اهتمام أصحاب القرار بتتمية مهارات المشرفات التربويات في التخطيط - التدريب - التقويم وكذلك تنمية قدراتهن الشخصية .

10. أن يتم تغيير محتويات سجل المشرف التربوى بما يتتاسب مع مهامه الأساسية ( وأن يتم متابعة السجل في منتصف كل فصل دراسي ليتابع الإنجاز الذي حققه المشرف في تتفيذ خططه). 11. أن تسلم خطة المدرسة إلى المشرف التربوى الذى سيشرف على المدرسة مستقبلا لتتابع ما أنجزته مشرفة الددرسة الحالية ( فتكون عملية التحسين و التطوير عملية مستمرة ). 
المعلم في المدرسة يحتاج إلى التقدير والاحترام ، وخير ما يحقق له ذلك هو المشرف التربوي ، كما

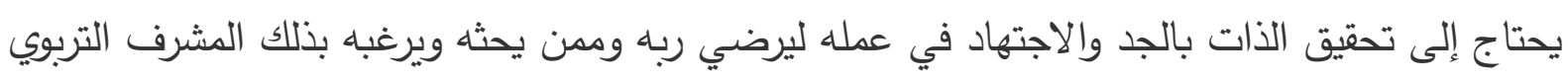

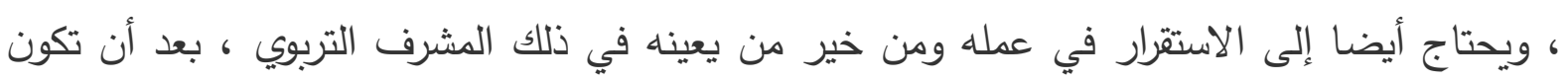

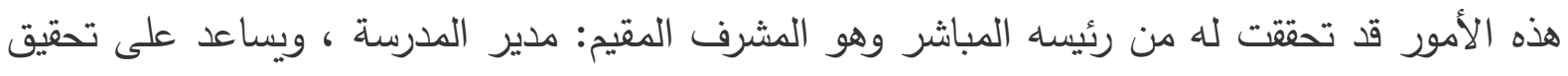

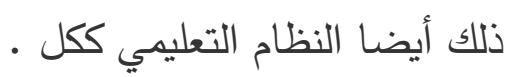

والتحفيز أو الحافز يقع ضمن الإطار الفلسفي للعلاقات الإنسانية الذي يتكون من: الحافز ، والاختلافات الفردية، والمصلحة المشتركة ، والكرامة الإنسانية. وليس معنى العلاقات الإنسانية مجرد البشاشة الإنة الإنسانة والابتسامة والسذاجة في التعامل وإنما التحفيز في ميدان العمل والإدارة هو : عملية تتشيط واقع الأفراد

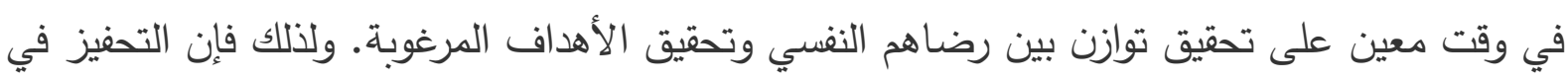
علم الإدارة التربوية يشمل : دراسة سلوك الفرد وتحديد العوامل المؤثرة في سلوكه، والتأثير في سلوكانه لتحقيق أهداف محددة.

\section{مراجع البحث}

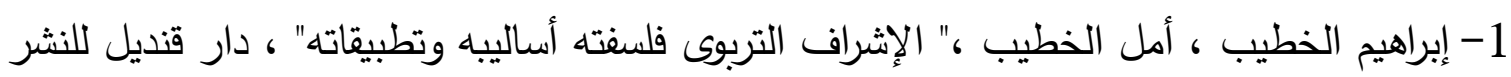

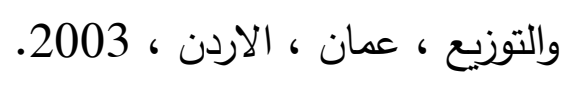

2- إبراهيم عصدت مطاوع،" الإدارة التربوية فى الوطن العربى، أوراق عربية وعالمية، مكتبة

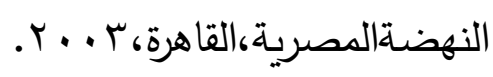

3- أحمد اسماعيل حجى : كلمة افتتاحية المؤتمر السنوى الخامس أخلاقيات الادارة التعليمية،

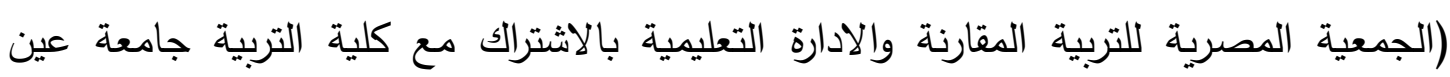

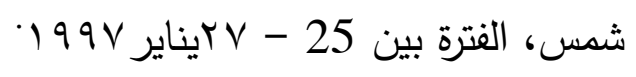

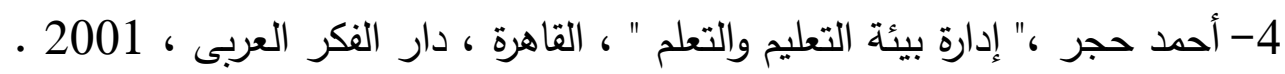

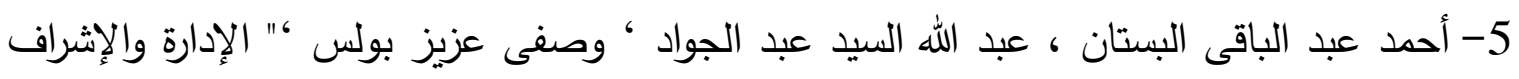

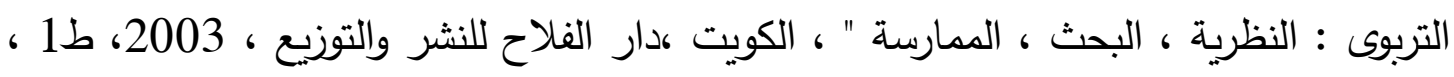

ص 334

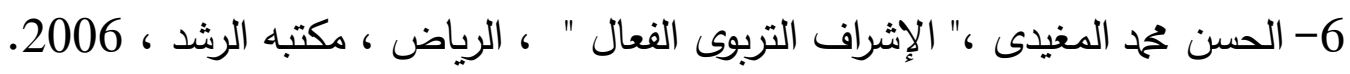

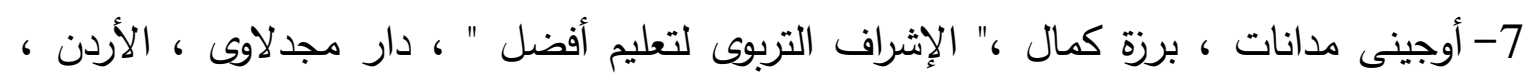
.2002

8- جودت عزت عطوى ،" الإدارة التعليمية والإشراف التزبوى أصولها وتطبيقاتها " ، دار الثقافة للنشر والتوزيع ، 2015 ـ 
9- حسن الطعانى ،" الإشراف التربوى (مفاهيمه - أهدافه- أسسه- أساليبه) "، مراجعه أحمد بطاح

2005 ،

10- خالد الثهرى،" تجديد الإثراف التربوى "، الدمام ، مكتبه الملك فهر الوطنية للنشر ،

.2014

11- إفده الحريرى ،"الإشراف التربوى واقعه وآفاقه المستقبلية" ، عمان ، الأردن ، دار

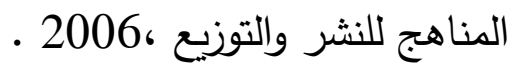

12- سلامه عبد العظيم حسين ، عوض الله سليمان عوض الله ،" إتجاهات حديثة فى

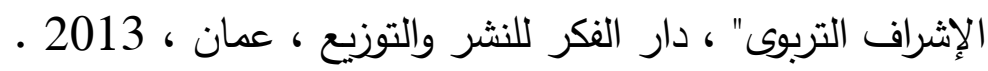

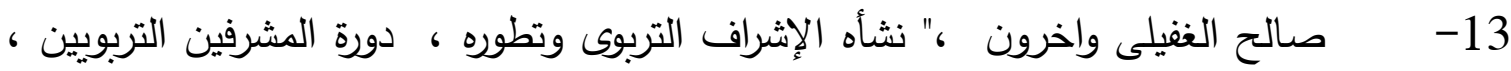

كلية التربية ، جامعه الملك سعود “، الفصل الدراسى الثانى ، 2007 (2018/8/13)

14- طارق عبد الحميد البدرى : " تطبيقات ومفاهيم فى الاشراف التربوى " ، دار الفكر

للطباعه والنشر ، 2001.

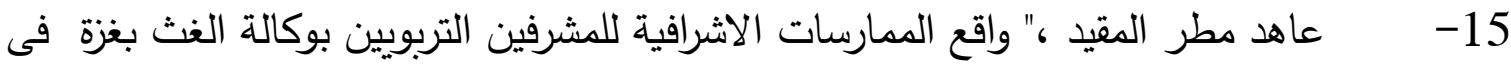

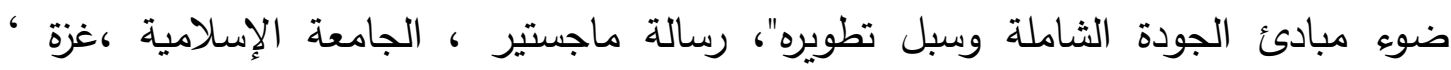

.2006

16- عبد الرحمن عبدالله العبد الجبار ،" الإشراف التربوى وتمهين المعلمين وتوطين الإثراف

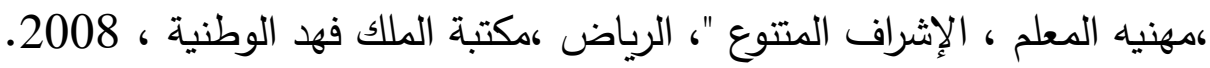

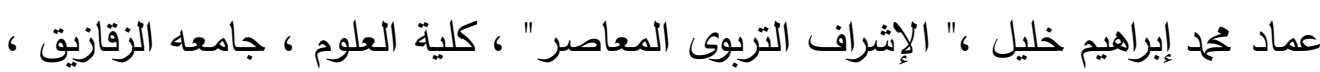

18- محمد بدر صيام ،" دور أساليب الإثراف التربوى فى تطوير الأداء المهنى للمعلمين فى

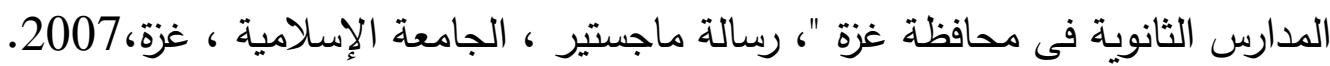

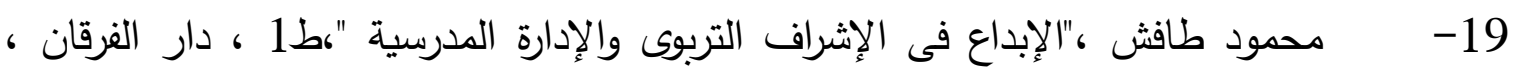

عمان ،2004

20- مدحت محم أبو النصر : الخدمة الاجتماعية في المجال الدرسي ، المجموعة العربية

للتدريب والنشر ، القاهرة ، 2020.

21- - نادر سعيد ،أبستمولوجيا المعرفة ،العلاقة الجدلية بين التنمية الانسانية ومجتمع المعرفة

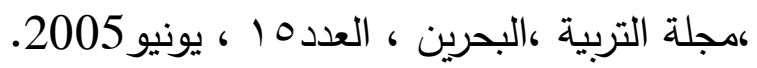

ثانيا : المراجع الأجنبية

1- Ehren ,M. C.M. \&Leeuw,F.L(2005).On the impact of the Dutch Educational Supervision Act Analyzing Assumptions Concerning The inspection of 
Primary Education inspection of primary .Journal Education American of Evaluation .vol.(26), No. 1.(60-76).

$$
\text { ثالثا : مواقع شبكة المعلومات الدولية ( الإنترنت ) }
$$

1- http://www.shatharat.net/vb/showthread.php?t=9297 